\title{
Inhibition of temperature runaway phenomenon in the Sabatier process using bed dilution structure: LBM-DEM simulation
}

Yixiong LIN ${ }^{1}$, Chen Yang ${ }^{2}$, Cheolyong Choi ${ }^{1}$, Wei Zhang ${ }^{3}$, Kazui Fukumoto ${ }^{1}$, Hiroshi Machida $^{1}$, and Koyo Norinaga ${ }^{1}$

${ }^{1}$ Nagoya University

${ }^{2}$ Fuzhou University

${ }^{3}$ China University of Petroleum Beijing

January 21, 2021

\begin{abstract}
The Sabatier process is promising for carbon dioxide utilization and energy storage. However, the serious problem that limits more comprehensive industrial applications is catalyst deactivation due to the temperature runaway phenomenon. The inert particle dilution approach, including the mixing dilution method and layered dilution method is applied to solve this problem. Based on the lattice kinetic scheme-lattice Boltzmann method (LKS-LBM), the effects of three parameters in bed dilution structure reconstructed by the discrete element method (DEM) on temperature distribution and carbon conversion rate were discussed, so as to investigate the relationship between packing structure and temperature distribution. Furthermore, numerical results indicated that an optimal bed dilution structure, which not only can control the peak temperature below the critical temperature to avoid coking and sintering of catalyst, but also can improve the carbon conversion rate by almost $18 \%$ compared with the structure without dilution under the same circumstance.
\end{abstract}

\section{Hosted file}

Text for AIChE.pdf available at https://authorea.com/users/391038/articles/505231-inhibitionof-temperature-runaway-phenomenon-in-the-sabatier-process-using-bed-dilution-structurelbm-dem-simulation

\section{Hosted file}

Figures for AIChE.pdf available at https://authorea.com/users/391038/articles/505231inhibition-of-temperature-runaway-phenomenon-in-the-sabatier-process-using-bed-dilutionstructure-lbm-dem-simulation

\section{Hosted file}

Tables for AIChE.pdf available at https://authorea.com/users/391038/articles/505231inhibition-of-temperature-runaway-phenomenon-in-the-sabatier-process-using-bed-dilutionstructure-lbm-dem-simulation 